\title{
Parenting and child behaviour barriers to managing screen time with young children
}

This is a post-peer-review, pre-copyedit version of an article published the Journal of Child and Family Studies.

The final authenticated version is available online at: http://dx.doi.org/ 10.1007/s10826-020-01881-4

Manuscript Accepted 22 November 2020

Samuel Halpin • Amy E. Mitchell*• Sabine Baker • Alina Morawska

Parenting and Family Support Centre, School of Psychology, The University of Queensland, Brisbane, Australia

Running head: Parenting, child behaviour, and screen time

\section{Funding:}

This work was supported by the Australian Research Council (DP140100781) and a Children's Hospital Foundation Early Career Fellowship (AEM; award ref. no. 50223).

\section{Acknowledgements:}

Sincere thanks to the parents who participated in this study.

\section{Conflict of Interest Statement:}

The Parenting and Family Support Centre is partly funded by royalties stemming from published resources of the Triple P - Positive Parenting Program, which is developed and owned by The University of Queensland (UQ). Royalties are also distributed to the Faculty of Health and Behavioural Sciences at UQ and contributory authors of published Triple P resources. Triple P International (TPI) Pty Ltd is a private company licensed by Uniquest Pty Ltd on behalf of UQ, to publish and disseminate Triple P worldwide. The authors of this report have no share or ownership of TPI. Dr Morawska receives royalties from TPI. TPI had no involvement in the study design, collection, analysis or interpretation of data, or writing of this report. Dr Mitchell, Dr Baker, and Dr Morawska are employees at UQ.

*Corresponding author: A.E. Mitchell, Parenting and Family Support Centre, School of Psychology, The University of Queensland, 13 Upland Road, St Lucia, 4072, Australia. Email: a.mitchell5@uq.edu.au 


\begin{abstract}
The impact of excessive screen use on child health and development is now a public health concern, and research efforts are focused on finding ways to moderate screen use. To date, the focus has mainly been on school-aged children and adolescents, and the early childhood context has been comparatively neglected. Moreover, relationships between factors likely to influence screen use by young children (e.g., child behaviour, parenting style and self-efficacy) remain largely unexplored. Our study aimed to test relationships between parenting style, parents' self-efficacy, parental distress, child behaviour, and young children's screen time. We used a cross-sectional study design. Parents $(N=106)$ of young children (aged 0-4 years) living in Australia completed an online survey which assessed parent-reported child screen use, screen time-related child behaviour problems, parents' self-efficacy for managing child behaviour and screen time, parents' beliefs about the positive/negative effects of screen time, parenting style, general child adjustment and parent efficacy, and parent distress. Correlation coefficients revealed relationships between dysfunctional parenting styles, screen timerelated child behaviour problems, and parent self-efficacy for dealing with these behaviours. Using hierarchical multiple regression models, children's screen time behaviour problems explained the greatest variance in parents' self-efficacy for managing screen time, and parents' self-efficacy for managing child screen time explained the greatest variance in parent-reported child screen time. Further research is needed to disentangle these relationships; however, preliminary results suggest that child behaviour difficulties and parents' selfefficacy warrant further investigation as potentially useful targets for interventions aiming to improve screen use in early childhood.
\end{abstract}

Keywords: child behaviour; parenting; self-efficacy; media use; young children

- Dysfunctional parenting styles (laxness, overreactivity) correlated with greater screen time-related child behaviour problems.

- Screen time-related behaviour problems were the strongest predictor of low parental self-efficacy for managing screen time.

- Low self-efficacy for managing screen time was the strongest predictor of children's (parent-reported) screen time. 
Rapidly increasing exposure of children to screen devices in day-to-day life has raised questions about the potential impacts on children's short- and longer-term health and development (Anderson, Economos, \& Must, 2008; Atkin, Corder, \& van Sluijs, 2013; Laurson et al., 2008; Marques, Calmeiro, Loureiro, Frasquilho, \& de Matos, 2015), and evidence supporting the importance of limiting children's screen use is accumulating. A recent systematic review of 13 systematic reviews of cross-sectional and longitudinal studies (Stiglic \& Viner, 2019) revealed relationships between higher levels of screen use and poorer psychological health, including depressive symptoms, behaviour problems, anxiety, hyperactivity/inattention; poorer self-esteem, wellbeing, and quality of life; and poorer cognitive development, educational attainments, and sleep. In contrast, there was no consistent evidence of benefits to children's health, wellbeing, or development.

Although most research has focused on school-aged children or adolescents, exposure of younger preschool-aged children to screen media may also be problematic. A systematic review focusing on younger children (under 5 years of age) analysed the results from 21 longitudinal and experimental studies, identifying relationships between increased screen use and poorer cognitive development, poorer psychosocial health, and greater adiposity/BMI (LeBlanc et al., 2012). Importantly, there is emerging evidence of a dose-response relationship between screen time and poorer outcomes for young children (LeBlanc et al., 2012; Zhao et al., 2018), and exposure to screen media in early childhood is linked with greater exposure in later childhood (Xu, Wen, Hardy, \& Rissel, 2016).

A recent national child health poll found that most Australian parents feel their children are spending too much time using screen devices (Rhodes, 2017). Guidelines from the American Academy of Pediatrics (AAP, 2016) recommend screen media use (besides video-chatting) be avoided for children younger than 18 months. For parents who elect to introduce screen media from 18 months to 2 years of age, the current recommendation is to limit this to high quality programming with parental supervision and explanation. It is further recommended that children aged 2-5 years have no more than an hour of screen time per day, with this to be supervised and interactive. These guidelines are comparable to those recently issued by the World Health Organisation (2019), which recommend no screen exposure for infants 12 months and under, and only up to an hour per day for two- to four-year-olds. The majority (93\%) of children exceed these recommendations (Hume et al., 2019), and parents report that their child's screen use is associated with family conflict (62\%), oppositional behaviour (32\%), lack of physical activity (43\% for teenagers, $18 \%$ for pre-schoolers), and sleep problems (26\%) (Rhodes, 2017). As many as 17\% of parents report conflict and arguments between family members over screen use most days of the week (Rhodes, 2017). 
The link between parenting and child health behaviours and outcomes across a number of child health domains is now well-established (Case \& Paxon, 2002; Morawska, Calam, \& Fraser, 2015; Park \& WaltonMoss, 2012; Schary, Cardinal, \& Loprinzi, 2012; Skouteris et al., 2011; Yee, Lwin, \& Ho, 2017), and parents also have a vital role to play in guiding children to develop healthy screen use habits. Cross-sectional and longitudinal studies have identified numerous parent-level factors associated with high or problematic levels of screen use by young children, including parents' own screen time and attitudes towards screen use, low parental monitoring/restriction of screen use, and low parental self-efficacy for reducing/limiting children's screen time (Goncalves, Byrne, Viana, \& Trost, 2019; Lauricella, Wartella, \& Rideout, 2015; Tang, Darlington, Ma, \& Haines, 2018; Xu, Wen, \& Rissel, 2015), and there is some evidence that reduced parent-child interaction could mediate the link between excessive screen use and children's psychosocial wellbeing (Zhao et al., 2018).

In terms of parenting behaviours, parental monitoring and restriction of children's screen use is associated with less screen time (Downing, Hinkley, \& Hesketh, 2015; Lampard, Jurkowski, \& Davison, 2013; Lloyd, Lubans, Plotnikoff, Collins, \& Morgan, 2014; Thompson, Vandewater, Matson, \& Tschann, 2015). Conversely, behavioural control and co-viewing are associated with more screen time for pre-school aged children (Thompson et al., 2016). Parenting styles have also been linked with variations in child screen use, and both authoritarian and permissive parenting styles have been associated with more screen time for school-aged children (Langer, Crain, Senso, Levy, \& Sherwood, 2014), whereas authoritative parenting has been associated with less screen time (Schary et al., 2012; Veldhuis, van Grieken, Renders, HiraSing, \& Raat, 2014). These patterns support the broader literature pinpointing parenting style and behaviour as an important predictor of child behaviour problems (Pinquart, 2017), as well as child health behaviours and outcomes more broadly (Adamson \& Morawska, 2017; Morawska, Mitchell, Burgess, \& Fraser, 2017; Owens-Stively et al., 1997).

While many parents place limits around their child's screen use, this parenting task presents a significant challenge (Hardy, Hector, Saleh, \& King, 2016). Although new parents of infants tend to be quite optimistic about their ability to manage their child's screen use, by the preschool years many parents have become resigned to using strategies that “work", even when not ideal (Hesketh, Hinkley, \& Campbell, 2012). For example, a survey of 1,977 Australian parents (Rhodes, 2017) found that $61 \%$ of parents of pre-schoolers report using screen devices to manage their child's behaviour when out and about, $62 \%$ report using screens to reward good behaviour, and 70\% report using these devices to distract their child while accomplishing other tasks. Notably, parental use of screen time as rewards or punishments for appropriate or inappropriate child behaviour is also associated with greater overall screen use by children (Tang et al., 2018). 
Self-efficacy, a key construct of Social Cognitive Theory (Bandura, 2001), has also been linked with variations in parenting behaviour and screen time management in early childhood. In the parenting and family context, social cognitive theory recognises the bidirectional influences that exist between personal factors (e.g., parental stress, beliefs, attitudes), environmental factors (e.g., availability of resources), and individual behaviour (e.g., parenting behaviours). Parenting self-efficacy, related to parenting confidence, is an important predictor of actual parenting behaviour, including parenting behaviour relevant to child health (Sanders \& Woolley, 2005), and is defined as "beliefs or judgements a parent holds in their capabilities to organise and execute a set of tasks related to parenting a child" (Montigny \& Lacharite, 2005, p.387). Bandura proposed that, given adequate skills and incentives, an individual's reaction to challenging situations and the amount of effort and persistence they show in that situation will largely be determined by their self-efficacy beliefs (Bandura, 1977, 1997).

Although research examining parents' self-efficacy for managing screen time in young children is scarce, available evidence suggests that maternal self-efficacy to limit screen time is inversely associated with screen time exposure in 1-year-old and 5-year-old children (Campbell, Hesketh, Silverii, \& Abbott, 2010). Likewise, mothers with persistently high (when their children were both 4 and 19 months old) or increasing (an increase from 4 months to 19 months) self-efficacy for limiting children's television viewing had children with lower television viewing (Hnatiuk, Salmon, Campbell, Ridgers, \& Hesketh, 2015). However, previous research has been hampered by self-efficacy measures that are incongruent with Bandura's definition and recommendations around self-efficacy measurement (Bandura, 2006), and to the best of our knowledge no research to date has examined predictors of parental self-efficacy (e.g., parental adjustment, parenting style, child behaviour) in this context.

Parental mental health is another parent-level factor which may influence the degree to which parents can successfully manage their young child's screen use. Previous research shows that maternal distress/depression correlates with greater screen use by young children (Duch, Fisher, Ensari, \& Harrington, 2013; Hoyos Cillero \& Jago, 2010). Conversely, fewer parent life pressures and greater social support are associated with meeting screen time recommendations (Lampard et al., 2013). It is unclear, however, what mechanisms are at play when looking at these correlations. Relationships between parental distress (depression, anxiety, stress) and parental self-efficacy may be an important consideration, given that parent distress tends to negatively correlate with self-efficacy, both in terms of general parenting self-efficacy and in dealing with problem behaviours (Sanders \& Woolley, 2005) and across a range of parenting behaviours relevant to child 
health outcomes (Mitchell, Fraser, Morawska, Ramsbotham, \& Yates, 2016; Mitchell, Fraser, Ramsbotham, Morawska, \& Yates, 2015; Streisand, Swift, Wickmark, Chen, \& Holmes, 2005).

Child behaviour may also influence parent self-efficacy and actual parenting behaviour. Previous research has established that challenging child behaviour is linked with poorer parent self-efficacy for managing screen time (Hnatiuk et al., 2015) as well as other child health-related activities (Mitchell et al., 2016; Mitchell et al., 2015). Despite evidence confirming the prevalence of family conflict over screen use and oppositional child behaviours associated with screen use (Rhodes, 2017), to date no research has examined the relationships between parenting style, child behaviour, parents' self-efficacy with managing children's screen time, and screen use by young children.

There is an emerging literature examining the importance of parents and parenting in helping young children to develop important health-related skills, attitudes, and habits from the earliest years to improve children's short- and longer-term health outcomes (Baker, Morawska, \& Mitchell, 2019). With children developing habits around screen use from a very young age that are likely to persist into later childhood and beyond, it is important to examine potential targets for intervention that foster the development of healthy screen use habits in early childhood. Taking a socioecological perspective on the development of healthy habits in childhood (Bronfenbrenner, 1992) and acknowledging the tremendous influence that parents have over the health and lifestyle behaviours of young ( 0 - to 4-year-old) children, it is important to examine parents' beliefs and behaviours as potential targets for intervention with children in this age group.

The overall purpose of this study was to examine relationships between parenting style, self-efficacy, child behaviour, parent distress, and screen time in young children, and to identify important variables predicting self-efficacy for managing children's screen time, and actual screen use in young children. Based on theory (Bandura, 2001; Bronfenbrenner, 1992) and prior literature in the broader parenting field (Mitchell et al., 2016; Mitchell et al., 2015; Sanders \& Woolley, 2005; Streisand et al., 2005), we hypothesised that (H1) parenting style and (H2) parent distress (depression, anxiety, stress) would be correlated with children's screen time behaviour difficulties and parents' self-efficacy for managing children's screen time behaviour difficulties; and that children's screen-time behaviour difficulties and parents' self-efficacy for managing children's screen time behaviour difficulties would explain variation in (H3) parents' self-efficacy for limiting their child's screen time and (H4) children's parent-reported screen time, over and above variation explained by other parent and child variables. 


\section{Methods}

\section{Participants and Procedure}

Participants were parents (18 years or older) of children aged 0-4 years living in Australia. There were no other exclusion criteria. Ethics clearance was granted by [removed for blinded review] Human Research Ethics Committee. Participants were recruited via advertisements on social media, popular Australian parenting forums and websites, and emails sent out to childcare centres Australia-wide, which directed interested parents to the study webpage for detailed information about the study and a link to the online survey. Parents could enter a draw to win one of two $\$ 50$ department store gift vouchers.

Participants consented and completed the survey online between May and August 2018. The survey took on average 24 minutes to complete. Those with multiple children aged 0-4 years were directed to respond to the survey for only one child - specifically, the child about whom they had the greatest concerns regarding screen use. If they had no concerns, they focused on their eldest child within the age range.

Of 129 eligible respondents, 23 did not complete beyond the initial demographics section and were removed, leaving a final sample of 106 participants. Demographic characteristics of participants are presented in Table 1. Participants were 22 to 45 years old, and target children were aged between 1 month and 4 years, 11 months. Most respondents were university-educated mothers, in committed relationships, with 1 or 2 children, and in full- or part-time employment. Few reported financial difficulties, and few had sought help for their child's social, emotional, or behavioural problems in the past 12 months. Most target children were living in only one household, with their original family, and there were similar numbers of boys and girls. Overall, the sample had a higher proportion of female and university-educated respondents and two-parent households compared to the broader population of Australian parents (Australian Bureau of Statistics, 2015; Australian Bureau of Statistics, 2019).

$<$ Insert Table 1 about here>

\section{Measures}

The Family Background Questionnaire (FBQ; Sanders \& Morawska, 2010) collected demographic data including parent and child age and gender, relationship status and household structure, and sociodemographic indicators including education, employment, income, and post code.

The Children's Screen Time History Questionnaire (CSTHQ; Mitchell \& Halpin, 2018) collects details 
about child and parent screen time use. Items assess current daily limits on children's screen use (in hours) on week days and weekend days; children's actual (parent-reported) screen use; types of screen devices used; parental concern around their child's screen use (yes/no); and parents' views on their child's current screen use ("I think my child should be having more screen time"/“I think my child should be having less screen time"/“I think my child has about the right amount of screen time").

The Screen Time Behaviour Checklist (STBC; A. E. Mitchell, Halpin, Morawska, \& Baker, 2018) is an 18-item parent-report questionnaire used to assess child behaviour problems related to managing children's screen time, and parents' self-efficacy for dealing with these problems. The instrument comprises two factors: Oppositional Behaviour (10 items; e.g. "Complains or whinges about wanting screen time") and Reliance on Screens ( 8 items; e.g. "Has trouble finding interesting or enjoyable things to do without screens"). Parents rate the extent to which each behaviour has been a problem for them with their child over the past 4 weeks from 1 ("not at all") to 7 ("very much"). Item scores are summed to generate a total Extent score, with higher scores indicating greater child behaviour difficulties. Parents then rate how confident they are that they can successfully deal with each behaviour from 1 ("certain I can't do it") to 10 ("certain I can do it"). Item scores are summed to generate a total Confidence score, with higher scores indicating greater self-efficacy with managing difficult behaviours. Respondents could also enter up to 4 additional behaviours and rate each using the Extent and Confidence scales. Both the Extent and Confidence scale total scores showed excellent internal consistency ( $\alpha=.93$ and .97 , respectively) in the current sample.

The Screen Time Self-Efficacy Scale (STSES; Halpin, Mitchell, Baker, \& Morawska, 2018) is a 14item scale used to assess parents' self-efficacy for managing their child's screen time under various challenging or stressful circumstances. The measure was constructed according to Bandura's Guide for Constructing SelfEfficacy Scales (2004) and provides a series of items that assess domain-level self-efficacy. The instrument comprises two factors: Parental Strain (7 items; e.g., "When I am tired"), and Contextual Factors (6 items; e.g. “On holidays"). Parents respond to each item using a 10-point Likert scale from 1 (“certain I can't do it") to 10 ("certain I can do it"), and items are summed to generate a total score, with higher scores indicating greater selfefficacy. The total score showed excellent internal consistency $(\alpha=.94)$ in the current sample.

The Effects of Children's Screen Time Scale (ECSTS; Mitchell, Baker, Morawska, \& Halpin, 2018) is a 23-item scale used to assess the effects that parents perceive their child's current screen use has on various aspects of their child's health, development, and daily functioning, and on their own wellbeing. The instrument 
comprises four factors: Child Functioning ( 8 items; e.g. "My child's overall behaviour”), Child Development (7 items; e.g. "My child's early learning [e.g. colours, numbers, letters]"), Parent-Child Interaction (5 items; e.g. "How patient I am with my child"), and Parent Self-Care (3 items; e.g. "How easily I can take a break while caring for my child"). Parents rate the overall effect they perceive their child's current use of screens has for each item using an 11-point Likert scale ranging from -5 (extremely negative) to +5 (extremely positive), with a mid-point anchor of 0 (no effect), and raw scores are converted to item scores between 0 to 10 (with a mid-point [neutral] score of 5) for analyses. For scale totals, the item mean score was calculated to give an overall score of how positively or negatively the participant perceived their child's screen use, with higher and lower scores indicating perceptions of more positive and negative effects, respectively. The total score showed excellent internal consistency $(\alpha=.94)$ in the current sample.

The Parenting Scale (PS; Arnold, O'Leary, Wolff, \& Acker, 1993) is a 30-item scale that measures parents' use of dysfunctional discipline styles, with subscales of Laxness, Overreactivity, and Verbosity. Respondents use a 7-point scale to indicate the degree to which each statement describes them over the past 2 months (e.g., "I am the kind of parent that...sets limits on what my child is allowed to do [effective anchor] lets my child do whatever he or she wants [ineffective anchor]"), with higher scores indicating less effective parenting. Parents scoring higher than $1 \mathrm{SD}$ above mean scores in a non-clinic population (i.e. Laxness $>3.2$, Overreactivity $>3.1$, Verbosity $>4.1$, total score $>3.2$ ) are considered to be in the elevated range on this measure. The Laxness and Overreactivity subscales and the PS Total showed good internal consistency $(\alpha=.84, .81$, and .87 respectively) in the present sample; however, the Verbosity subscale showed poor internal consistency ( $\alpha=$ $.56)$ and was therefore omitted from analyses.

The Child Adjustment and Parent Efficacy Scale (CAPES; Morawska, Sanders, Haslam, Filus, \& Fletcher, 2014) is a 27 -item scale used to assess child behaviour problems, emotional maladjustment, and parental self-efficacy with managing these. The first 19 items represent common child behaviour problems and are rated from 0 ("not at all [true of my child]") to 3 ("very much [true of my child]"). Each of these first 19 items is accompanied by a self-efficacy rating of parent's confidence in managing that specific behaviour, from 1 (“certain I can't do it") to 10 (“certain I can do it"). The remaining eight child adjustment items are positively worded and rated on a 4-point Likert scale from 0 ("not at all [true of my child]") to 3 ("very much [true of my child]"). The total Intensity score is the sum of both the Behaviour and Emotional Maladjustment subscale scores, and higher scores for Intensity and Self-Efficacy scales indicate greater child behavioural and emotional problems and greater self-efficacy for managing these, respectively. The Emotional Maladjustment, Behaviour 
and total Intensity scales all showed adequate internal consistency $(\alpha=.74, .79$ and .80 respectively) with the current sample. The Self-Efficacy scale showed excellent internal consistency in the current sample $(\alpha=.98)$.

The short form of the Depression Anxiety and Stress Scale (DASS; Lovibond \& Lovibond, 1995) is a 21-item self-report scale, which measures depression, anxiety and stress symptoms in adults. Respondents indicate from 0 (did not apply to me at all) to 3 (applied to me very much, or most of the time) the degree to which they experienced symptoms over the past week. Total scores range from 0 to 42, with higher scores indicative of greater symptoms. For the current study, scores were also summed to give an overall Distress score. In the current sample, the overall Distress scale, as well as the Depression and Stress subscales showed good internal consistency ( $\alpha=.89, .81$, and .85 respectively). The Anxiety subscale showed acceptable internal consistency $(\alpha=.70)$.

\section{Data Analyses}

Overall there were $13.8 \%$ missing data. The pattern of missing data was monotonic, and values were Missing Completely at Random (MCAR) as determined by Little's MCAR test: $\chi^{2}(5717)=3577.94, p>.99$. Estimation Maximisation (EM) was used to replace missing data. Parametric and non-parametric tests were used for normally distributed and non-normally distributed data, respectively. Hierarchical regression models were used to test which key variables explained variation in parents' self-efficacy for limiting their child's screen time (STSES) and the child's average daily screen time, to test Hypotheses 3 and 4. Both regression models accounted for potentially important demographic variables (child age, parent financial difficulties, and parent education). The a priori power analysis indicated that a sample size of 74 would be sufficient to achieve $90 \%$ power with an error probability of $5 \%$ in detecting a large effect size $\left(f^{2}=0.35\right)$ in the hierarchical multiple regression model with 12 predictor variables. Data were analysed using SPSS version 25, and statistical significance was set at $p<.05$.

\section{Results}

\section{Children's Screen Time History}

Parent-reported screen time limits, as well as actual child screen time are described in Table 2.

Children's screen use (parent-reported) averaged 1 hour 19 minutes per day, with almost double the amount of daily screen use on weekends ( 1 hour 55 minutes) compared to weekdays (1 hour 4 minutes). Most participants $(68.9 \%, 73)$ reported setting limits on their child's screen time. Overall, $46.6 \%$ (41) of parents reported being 
concerned about their child's screen use, and 51.7\% (45) of parents thought their child should be having less screen time. The remaining $48.3 \%$ (42) thought their child was having about the right amount of screen time. No participants responded that they thought their child should be having more screen time. Parents reported the most common screen devices used by children were television $(85.8 \%, 91)$, tablets $(47.2 \%, 50)$, and smartphones $(42.5 \%, 45)$; less common were laptops $(10.4 \%, 11)$, personal computers $(6.6 \%, 7)$, and gaming consoles $(3.8 \%, 4)$.

$<$ Insert Table 2 about here $>$

\title{
Main Analyses
}

Descriptive statistics for child variables are summarised in Table 2. Descriptive statistics for parent variables are summarised in Table 3. Correlations between the major variables of interest are presented in Table 4. Given that the vast majority of respondents (95.3\%) were mothers, post-hoc sensitivity analyses excluding fathers were conducted, revealing no difference in results compared to analyses for the full sample. All participants (including fathers and other caregivers) were therefore retained.

\section{Hypothesis 1}

Consistent with predictions, Laxness, Overreactivity, and the Parenting Scale Total score were all positively correlated with intensity of screen time behaviour difficulties (STBC Intensity) and negatively correlated with parents' self-efficacy for managing these difficulties (STBC Confidence). PS Total scores showed weak positive relationships with screen time behaviour difficulties (Spearman's $\rho=.25$ to .35 ) indicating that higher scores for difficult child behaviours around screen time were associated with higher scores for ineffective parenting. PS scores showed weak to moderate negative relationships with parent self-efficacy for managing child screen time behaviour difficulties (Spearman's $\rho=-.34$ to -.48 ) indicating that higher scores for ineffective parenting were associated with lower confidence in dealing with screen time-related behaviour problems.

\section{Hypothesis 2}

Contrary to predictions, there was no correlation between parent distress (DASS Total scores) and screen time behaviour difficulties or parent self-efficacy for managing these difficulties. Neither were any relationships found between Depression, Anxiety, or Stress scores and these variables.

\author{
$<$ Insert Table 3 about here $>$ \\ $<$ Insert Table 4 about here $>$
}

\section{Regression models - Hypotheses 3 and 4}


Hierarchical regression models were used to test whether child screen-time behaviour difficulties and parents' self-efficacy for managing children's screen time behaviour difficulties would explain variation in parents' self-efficacy for limiting their child's screen time (Hypothesis 3) and parent-reported child screen time (Hypothesis 4), over and above variation explained by other parent (education, financial difficulties, laxness, overreactivity, self-efficacy for managing child behaviour) and child (age, emotional maladjustment, behaviour problems) variables.

Assumptions were tested, with no presence of multicollinearity and linearity, although Breusch-Pagan tests for heteroscedasticity resulted in significant Chi-square values for both models, indicating the possible presence of heteroscedasticity. A comparison of parameter estimates with robust standard errors using the HC3 method indicated a change in significance for several predictors within the models, so all confidence intervals are reported based on these robust standard errors. Several outliers based on elevated Mahalanobis and/or Cook's distances were investigated but insufficient evidence was found to justify their exclusion from analyses. Summaries of the regression models are shown in Table 5 and Table 6, respectively. Steps 1-3 were consistent across both models.

Hypothesis 3 tested predictors of parents' self-efficacy for limiting their child's screen time (see Table 5). The set of demographic variables in Model 1 significantly predicted self-efficacy for managing screen time $F(3,102)=3.02, p=.033$, accounting for $5.5 \%$ of the variance $\left(R_{a d j}^{2}=.055\right)$. Adding the parenting variables in Model 2 explained an additional $20.8 \%$ of the variance, $R_{a d j}^{2}=.263, F \Delta(3,99)=10.62, p<.001$, with laxness a significant independent predictor of parents' self-efficacy for managing screen time. Adding the child variables in Model 3 did not constitute a significant improvement on the previous model, $F \Delta(2,97)=0.92, p=.402$, accounting for no additional variance $\left(R^{2}{ }_{a d j}=.262\right)$, although Laxness remained a significant independent predictor of parents' self-efficacy. Addition of child screen time behaviour difficulties and parents' self-efficacy for managing screen time behaviour difficulties in Model 4 did significantly improve the model, accounting for $5.6 \%$ more variance, with the final model explaining a total of $31.8 \%$ of the variance, $R^{2}{ }_{a d j}=.318, F \Delta(2,95)=$ $4.99, p=.009$. In the final model, only screen time behaviour problems were a significant predictor of parents' self-efficacy for managing screen time, uniquely explaining $5.8 \%$ of the variance, providing partial support for Hypothesis 3.

Hypothesis 4 tested predictors of children's parent-reported screen time (see Table 6). The set of demographic variables in Model 1 significantly predicted children's screen time, $F(3,102)=8.28, p<.001$, accounting for $17.2 \%$ of the variance, with older child age a significant independent predictor of children's 
screen time. Addition of the parenting variables in Model 2 significantly improved the model, accounting for an additional $8.4 \%$ of the variance, $F \Delta(3,99)=4.84, p=.003$; although child age remained a significant predictor in Model 2, greater parental laxness was also a significant predictor of children's screen time. Adding the child variables in Model 3, $F \Delta(2,97)=6.92, p=.002$, and the screen time variables in Model 4, $F \Delta(2,95)=3.46, p=$ .035 , contributed an additional $8.0 \%$ and $3.2 \%$ of the unique variance, respectively, although no variables attained independent significance in either model. The final model (Model 5), in which parents' self-efficacy of managing screen time was added, resulted in improvement, accounting for a further $3.3 \%$ of variance, with the final model explaining $40.1 \%$ of the variance in children's screen time, $R^{2}{ }_{a d j}=.401, F \Delta(1,94)=6.36, p=.013$. Parents' self-efficacy for managing children's screen time was the only significant predictor in the final model, explaining only a small proportion of unique variance (3.6\%), but indicating that parent's self-efficacy for limiting their child's screen time predicts fewer hours of screen use.

\section{Discussion}

To date, few empirical studies have examined the role that child behaviour and parenting practices play in moderating screen use in young (pre-school aged) children. This study sought to extend knowledge in this area by using novel measures of screen time-related child behaviour difficulties, and parents' self-efficacy with managing children's screen time and screen time-related behaviours, to test the extent to which child behaviour and parenting variables explained variation in parents' self-efficacy for managing children's screen time, and children's parent-reported screen use.

Given the limitations of sample size $(N=106)$ and sample characteristics (predominantly mothers), results should be interpreted with caution. However, preliminary results revealed significant positive relationships between the use of ineffective parenting practices and children's screen time behaviour difficulties, with parents reporting more lax or overreactive parenting styles tending to score higher for intensity of screen time behaviour difficulties. Moreover, use of ineffective parenting was negatively associated with parents' selfefficacy for managing child screen time behaviour difficulties, with less effective parenting associated with lower self-efficacy with managing screen time. This is in line with the broader child behaviour and parenting literature demonstrating links between ineffective parenting practices and child behaviour difficulties in general (Morawska, Winter, \& Sanders, 2009), as well as in the child health context (Morawska, Stelzer, \& Burgess, 2008), and lower general and health-related parenting self-efficacy (Gross, Sambrook, \& Fogg, 1999; Mitchell et al., 2016; Morawska \& Sanders, 2007), and suggests that these relationships hold true in the screen time context. Importantly, though, the measure of screen time behaviour difficulties correlated more strongly with 
our outcomes of interest (parents' self-efficacy with managing screen time and children's screen time) compared to the general measure of child behaviour difficulties, and results provide tentative support for the use of situation-specific child behaviour measures to progress research in this area.

Unexpectedly, and in contrast to previous research (Duch et al., 2013; Hoyos Cillero \& Jago, 2010) we found no relationship between parents' psychological adjustment and child screen time behaviour difficulties or parents' self-efficacy for managing child screen time behaviour difficulties. Moreover, there were few relationships between parents' adjustment and any other variables, with the exception of (moderate strength) correlations with dysfunctional parenting total and subscale scores, raising the possibility that any relationship between parent distress and difficulties with managing child screen time could be mediated by parenting style and behaviour. This is congruent with recent research that has identified parent-child interaction as a potentially important mediator of the link between excessive screen use and children's psychosocial wellbeing (Zhao et al., 2018) and should be examined in future research.

Regression analyses revealed that children's screen time behaviour difficulties explained the greatest amount of unique variation in parents' self-efficacy for limiting screen time, over and above that explained by parents' self-efficacy for managing children's screen time behaviour difficulties and other key variables. To the best of our knowledge, this is the first study to examine these relationships in the screen-use context. Our results contrast with previous research which found that significant amounts of variation in parents' self-efficacy for engaging in health-related activities with their children (e.g., mealtimes, skin care, chronic illness management) tends to be explained by parents' self-efficacy with managing child behaviour problems related to the activity (Adamson \& Morawska, 2017; Mitchell et al., 2015). Scores for confidence with managing screen time behaviour difficulties were negatively skewed, with around a quarter of parents $(23.6 \%)$ scoring $100 \%$ confidence in their ability to manage problem screen time behaviours; this proportion remains unchanged even when children 12 months old or under were removed from the sample. In contrast, very few $(2.8 \%)$ were $100 \%$ confident in being able to manage screen time in various challenging situations. While a ceiling effect on the measure of parents' confidence with managing screen time behaviour difficulties may have contributed to this result, an alternative interpretation is that persistent, ongoing screen time behaviour difficulties may erode parents' confidence with limiting their child's screen time, even where a parent is confident in their ability to manage individual screen time behaviours. The relationship between intensity of screen time behaviour problems and confidence with managing them was only weak, and a subset of parents scored in the moderate range for intensity even with high confidence scores. Thus, parents are reporting confidence with managing 
problem behaviours, but the problem behaviours are still occurring at a moderate intensity. Taken together, these results suggest that offering practical support to parents to reduce screen time behaviour problems via the consistent use of effective, evidence-based strategies may help bolster parents' confidence with limiting children's screen time.

Finally, there was no evidence from this preliminary study that child screen time behaviour difficulties or parents' self-efficacy for managing children's screen time behaviour difficulties explained variation in children's parent-reported screen time, over and above variation explained by other parent and child variables. Self-efficacy for managing screen time was the only significant predictor of reported average daily screen usage, which is an important finding and supports the notion that self-efficacy may be a potentially important intervention target and process variable. Although children's screen time behaviour difficulties were not an independently unique predictor of screen time after other variables were taken into account, these preliminary results must be interpreted in the context of the result from the previous model which pinpointed child screen time behaviour as the strongest predictor of parents' self-efficacy with managing screen time. It may be that parents' self-efficacy with managing screen time mediates the relationship between child behaviour difficulties and actual screen use; however, these results should be interpreted with caution and further investigation with a larger and more diverse sample is required to answer this question.

Relatively few studies have tested approaches to reduce screen use by young children; these have largely focused on early education and school- or clinic-based studies and delivered mixed results (Schmidt et al., 2012; Wu, Sun, He, \& Jiang, 2016). Greatest improvements appear to be found for programs delivered in home- or clinic-based settings, however, underscoring the key role that parents play in intervention success (Schmidt et al., 2012). More recently, interventions seeking to reduce children's screen time via parenting interventions targeting parenting skills and confidence, responsive parenting and parent-child interaction have demonstrated positive effects on screen use (Adams et al., 2018; Sanders, Parent, \& Forehand, 2018), and our preliminary results provide some rationale for considering parenting skills and confidence with managing children's screen use behaviours as targets for future intervention research.

\section{Limitations}

Limitations are acknowledged. Children's screen use was assessed via parent-report, which may have resulted in under-estimation; use of objective methods of assessing screen use may improve measurement accuracy and reduce the effect of parent-report biases. The cross-sectional design of this study precludes any inference of causal relationships; future research will need to use longitudinal study designs to establish 
temporal relationships between variables. Although our relatively small sample size was sufficient to detect our pre-specified large effect sizes for multiple regression analyses, our ability to detect small- to medium-size effects was limited. The sample was self-selected, predominantly comprising well-adjusted, financially-secure, highly-educated mothers, which limits generalisability of findings to similar populations. Notably, parents in lower socioeconomic areas, with less education, and/or with poorer mental health may find managing child behaviour and screen use more challenging (Downing et al., 2015), and future research should focus on recruiting samples that are more representative of the broader population of Australian parents. Parents completed the questionnaire measures for their child about whom they had the greatest concerns about screen use, which could have potentially biased the results in favour of larger effect sizes. Finally, parents' own screen use was not measured in this study. Given the passive nature of much of young children's day-to-day screen exposure, future research should examine relationships between parents' beliefs, attitudes, and behaviours around their own screen use and that of their young children as a potential point of intervention to address this complex child and family health issue.

Data availability statement: Ethical constraints prevent data being made publicly available.

Author contributions: SH: designed and executed the study, conducted data analyses, and wrote the paper. AEM: designed and executed the study, wrote the paper. SB: collaborated with the design and writing of the study. AM: collaborated with the design and writing of the study. 


\section{References}

Adams, E. L., Marini, M. E., Stokes, J., Birch, L. L., Paul, I. M., \& Savage, J. S. (2018). INSIGHT responsive parenting intervention reduces infant's screen time and television exposure. International Journal of Behavioral Nutrition and Physical Activity, 15(24). doi:10.1186/s12966-018-0657-5

Adamson, M., \& Morawska, A. (2017). Early feeding, child behaviour and parenting as correlates of problem eating. Journal of Child and Family Studies, 26(11), 3167-3178.

Anderson, S. E., Economos, C. D., \& Must, A. (2008). Active play and screen time in US children aged 4 to 11 years in relation to sociodemographic and weight status characteristics: a nationally representative cross-sectional analysis. BMC Public Health, 8(1), 366. doi:10.1186/1471-2458-8-366

Arnold, D. S., O'Leary, S. G., Wolff, L. S., \& Acker, M. M. (1993). The Parenting Scale: a measure of dysfunctional parenting in discipline situations. Psychological Assessment, 5(2), 137.

Atkin, A. J., Corder, K., \& van Sluijs, E. M. F. (2013). Bedroom media, sedentary time and screen-time in children: a longitudinal analysis. International Journal of Behavioral Nutrition and Physical Activity, 10(1), 137. doi:10.1186/1479-5868-10-137

Australian Bureau of Statistics. (2015). Family characteristic and transitions 2012-13. Canberra: ABS.

Australian Bureau of Statistics. (2019). Education and work, Australia. Canberra: ABS.

Baker, S., Morawska, A., \& Mitchell, A. E. (2019). Promoting children's healthy habits through self-regulation via parenting. Clinical Child and Family Psychology Review, 22(1), 52-62.

Bandura, A. (1977). Self-efficacy: Toward a unifying theory of behaviour change. Psychological Review, 84(2), $191-215$

Bandura, A. (1997). Self-efficacy: the exercise of control. New York: W.H. Freeman and Company.

Bandura, A. (2001). Social cognitive theory: An agentic perspective. Annual Review of Psychology, 52(1), 126.

Bandura, A. (2006). Guide for constructing self-efficacy scales. In F. Pajares \& T. Urdan (Eds.), Self-efficacy beliefs of adolescents (pp. 307-337). Greenwich: Information Age Publishing.

Bronfenbrenner, U. (1992). Ecological systems theory. In Six theories of child development: Revised formulations and current issues (pp. 187-249). London, England: Jessica Kingsley Publishers.

Campbell, K., Hesketh, K., Silverii, A., \& Abbott, G. (2010). Maternal self-efficacy regarding children's eating and sedentary behaviours in the early years: Associations with children's food intake and sedentary behaviours. International Journal of Pediatric Obesity, 5(6), 501-508. doi:10.3109/17477161003777425

Case, A., \& Paxon, C. (2002). Parental behavior and child health. Health Affairs, 21(2), 164-178.

Downing, K. L., Hinkley, T., \& Hesketh, K. D. (2015). Associations of parental rules and socioeconomic position with preschool children's sedentary behaviour and screen time. Journal of Physical Activity \& Health, 12(4), 515-521. doi:10.1123/jpah.2013-0427

Duch, H., Fisher, E. M., Ensari, I., \& Harrington, A. (2013). Screen time use in children under 3 years old: a systematic review of correlates. International Journal of Behavioral Nutrition and Physical Activity, 10(1), 102. doi:10.1186/1479-5868-10-102

Goncalves, W. S. F., Byrne, R., Viana, M. T., \& Trost, S. G. (2019). Parental influences on screen time and weight status among preschool children from Brazil: a cross-sectional study. International Journal of Behavioral Nutrition and Physical Activity, 16(27), 1-8. doi:10.1186/s12966-019-0788-3

Gross, D., Sambrook, A., \& Fogg, L. (1999). Behavior problems among young children in low-income urban day care centres. Research in Nursing \& Health, 22, 15-25. 
Halpin, S., Mitchell, A. E., Baker, S., \& Morawska, A. (2018). Screen Time Self-Efficacy Scale. Brisbane: Parenting and Family Support Centre.

Hardy, L. L., Hector, D., Saleh, S., \& King, L. (2016). Australian middle eastern parents’ perceptions and practices of children's weight-related behaviours: Talking with Parents Study. Health \& Social Care in the Community, 24(5), e63-e71. doi:10.1111/hsc.12247

Hesketh, K. D., Hinkley, T., \& Campbell, K. J. (2012). Children's physical activity and screen time: qualitative comparison of views of parents of infants and preschool children. International Journal of Behavioral Nutrition and Physical Activity, 9, 152. doi:10.1186/1479-5868-9-152

Hnatiuk, J. A., Salmon, J., Campbell, K. J., Ridgers, N. D., \& Hesketh, K. D. (2015). Tracking of maternal selfefficacy for limiting young children's television viewing and associations with children's television viewing time: a longitudinal analysis over 15-months. BMC Public Health, 15(1), 517. doi: $10.1186 / \mathrm{s} 12889-015-1858-3$

Hoyos Cillero, I., \& Jago, R. (2010). Systematic review of correlates of screen-viewing among young children. Preventive Medicine, 51(1), 3-10. doi:https://doi.org/10.1016/j.ypmed.2010.04.012

Hume, C., Salmon, J., Veitch, J., O’Connell, E., Crawford, D., \& Ball, K. (2019). Children who meet recommendations for physical activity and screen-time despite socioeconomic disadvantage. Melbourne: Deakin University.

Lampard, A. M., Jurkowski, J. M., \& Davison, K. K. (2013). The family context of low-income parents who restrict child screen time. Childhood Obesity, 9(5), 386-392. doi:10.1089/chi.2013.0043

Langer, S. L., Crain, A. L., Senso, M. M., Levy, R. L., \& Sherwood, N. E. (2014). Predicting child physical activity and screen time: Parental support for physical activity and general parenting styles. Journal of Pediatric Psychology, 39(6), 633-642. doi:10.1093/jpepsy/jsu021

Lauricella, A. R., Wartella, E., \& Rideout, V. J. (2015). Young children's screen time: The complex role of parent and child factors. Journal of Applied Developmental Psychology, 36, 11-17. doi:10.1016/j.appdev.2014.12.001

Laurson, K. R., Eisenmann, J. C., Welk, G. J., Wickel, E. E., Gentile, D. A., \& Walsh, D. A. (2008). Combined influence of physical activity and screen time recommendations on childhood overweight. Journal of Pediatrics, 153(2), 209-214. doi:https://doi.org/10.1016/j.jpeds.2008.02.042

LeBlanc, A. G., Spence, J. C., Carson, V., Connor Gorber, S., Dillman, C., Janssen, I., .. . Tremblay, M. S. (2012). Systematic review of sedentary behaviour and health indicators in the early years (aged 0-4 years). Applied Physiology, Nutrition, and Metabolism, 37(4), 753-772.

Lloyd, A. B., Lubans, D. R., Plotnikoff, R. C., Collins, C. E., \& Morgan, P. J. (2014). Maternal and paternal parenting practices and their influence on children's adiposity, screen-time, diet and physical activity. Appetite, 79, 149-157. doi:https://doi.org/10.1016/j.appet.2014.04.010

Lovibond, P. F., \& Lovibond, S. H. (1995). The structure of negative emotional states: Comparison of the Depression Anxiety Stress Scales (DASS) with the Beck Depression and Anxiety Inventories. Behaviour Research and Therapy, 33(3), 335-343. doi:https://doi.org/10.1016/0005-7967(94)00075-U

Marques, A., Calmeiro, L., Loureiro, N., Frasquilho, D., \& de Matos, M. G. (2015). Health complaints among adolescents: Associations with more screen-based behaviours and less physical activity. Journal of Adolescence, 44, 150-157. doi:10.1016/j.adolescence.2015.07.018

Mitchell, A. E., Baker, S., Morawska, A., \& Halpin, S. (2018). Effects of Children's Screen Time Scale. Brisbane: Parenting and Family Support Centre.

Mitchell, A. E., Fraser, J. A., Morawska, A., Ramsbotham, J., \& Yates, P. (2016). Parenting and childhood atopic dermatitis: A cross-sectional study of relationships between parenting behaviour, skin care management, and disease severity in young children. International Journal of Nursing Studies, 64, 7285 . 
Mitchell, A. E., Fraser, J. A., Ramsbotham, J., Morawska, A., \& Yates, P. (2015). Childhood atopic dermatitis: A cross-sectional study of relationships between child and parent factors, atopic dermatitis management, and disease severity. International Journal of Nursing Studies, 52(1), 216-228. doi:https://doi.org/10.1016/j.ijnurstu.2014.09.008

Mitchell, A. E., \& Halpin, S. (2018). Children's Screen Time History Questionnaire. Brisbane: Parenting and Family Support Centre.

Mitchell, A. E., Halpin, S., Morawska, A., \& Baker, S. (2018). Screen Time Behaviour Checklist. Brisbane: Parenting and Family Support Centre.

Montigny, F., \& Lacharite, C. (2005). Perceived parental efficacy: concept analysis. Journal of Advanced Nursing, 49(4), 387-396.

Morawska, A., Calam, R., \& Fraser, J. (2015). Parenting interventions for childhood chronic illness: A review and recommendations for intervention design and delivery. Journal of Child Health Care, 19(1), 5-17.

Morawska, A., Mitchell, A., Burgess, S., \& Fraser, J. (2017). Randomized controlled trial of Triple P for parents of children with asthma or eczema: Effects on parenting and child behavior. J Consult Clin Psychol, $85(4), 283$

Morawska, A., \& Sanders, M. R. (2007). Concurrent predictors of dysfunctional parenting and maternal confidence: implications for parenting intervention. Child: Care, Health and Development, 33(6), 757767 .

Morawska, A., Sanders, M. R., Haslam, D., Filus, A., \& Fletcher, R. (2014). Child Adjustment and Parent Efficacy Scale: Development and initial validation of a parent report measure. Australian Psychologist, 49(4), 241-252. doi:doi:10.1111/ap.12057

Morawska, A., Stelzer, J., \& Burgess, S. (2008). Parenting asthmatic children: identification of parenting challenges. The Journal of Asthma, 45(6), 465-472.

Morawska, A., Winter, L., \& Sanders, M. R. (2009). Parenting knowledge and its role in the prediction of dysfuntional parenting and disruptive child behaviour. Child: Care, Health and Development, 35(2), 217-226.

Owens-Stively, J., Frank, N., Smith, A., Hagino, O., Spirito, A., Arrigan, M., \& Alario, A. J. (1997). Child temperament, parenting discipline style, and daytime behavior in childhood sleep disorders. Journal of Developmental and Behavioral Pediatrics, 18(5), 314-321. doi:10.1097/00004703-199710000-00005

Park, H., \& Walton-Moss, B. (2012). Parenting style, parenting stress, and children's health-related behaviors. Journal of Developmental and Behavioral Pediatrics, 33, 495-503.

Pinquart, M. (2017). Associations of parenting dimensions and styles with externalizing problems of children and adolescents: An updated meta-analysis. Developmental Psychology, 53(5), 873-932. doi:10.1037/dev0000295

Rhodes, A. (2017). Screen time: What's happening in our homes? Australian Child Health Poll. Melbourne: Royal Children's Hospital Melbourne.

Sanders, M. R., \& Morawska, A. (2010). Family Background Questionnaire. Brisbane: Parenting and Family Support Centre.

Sanders, M. R., \& Woolley, M. L. (2005). The relationship between maternal self-efficacy and parenting practices: implications for parent training. Child: Care, Health and Development, 31(1), 65-73. doi:doi:10.1111/j.1365-2214.2005.00487.x

Sanders, W., Parent, J., \& Forehand, R. (2018). Parenting to reduce child screen time: a feasibility pilot study. Journal of Developmental and Behavioral Pediatrics, 39(1), 46-54. 
Schary, D. P., Cardinal, B. J., \& Loprinzi, P. D. (2012). Parenting style associated with sedentary behaviour in preschool children. Early Child Development and Care, 182(8), 1015-1026. doi:10.1080/03004430.2012.678596

Schmidt, M. E., Haines, J., O'Brien, A., McDonald, J., Price, S., Sherry, B., \& Taveras, E. M. (2012). Systematic review of effective strategies for reducing screen time among young children. Obesity, 20(7), 1338-1354. doi:10.1038/oby.2011.348

Skouteris, H., McCabe, M., Swinburn, B., Newgreen, V., Sacher, P., \& Chadwick, P. (2011). Parental influence and obesity prevention in pre-schoolers: a systematic review of interventions. Obesity Reviews, 12(5), 315-328.

Stiglic, N., \& Viner, R. M. (2019). Effects of screentime on the health and well-being of children and adolescents: a systematic review of reviews. BMJ Open, 9, e023191.

Streisand, R., Swift, E., Wickmark, T., Chen, R., \& Holmes, C. S. (2005). Pediatric parenting stress among parents of children with Type 1 Diabetes: The role of self efficacy, responsibility, and fear. Journal of Pediatric Psychology, 30, 513-521.

Tang, L., Darlington, G., Ma, D. W. L., \& Haines, J., on behalf of the Guelph Family Health Study. (2018). Mothers' and fathers' media parenting practices associated with young children's screen-time: a crosssectional study. BMC Obesity, 5, 37. doi:10.1186/s40608-018-0214-4

Thompson, D. A., Johnson, S. L., Vandewater, E. A., Schmiege, S. J., Boles, R. E., Lev, J., \& Tschann, J. M. (2016). Parenting and preschooler TV viewing in low-income Mexican Americans: Development of the Parenting Practices Regarding TV Viewing (PPRTV) scale. Journal of Developmental and Behavioral Pediatrics, 37(6), 465-474. doi:10.1097/DBP.0000000000000309

Thompson, D. A., Vandewater, E. A., Matson, P. A., \& Tschann, J. M. (2015). Young low-income ethnic minority children watch less television when their mothers regulate what they are viewing. Acta Paediatrica, 104(3), 300-305. doi:10.1111/apa.12879

Veldhuis, L., van Grieken, A., Renders, C. M., HiraSing, R. A., \& Raat, H. (2014). Parenting style, the home environment, and screen time of 5-year-old children; The 'Be Active, Eat Right' Study. PLOS ONE, 9(2), e88486. doi:10.1371/journal.pone.0088486

World Health Organisation. (2019). Guidelines on physical activity, sedentary behaviour and sleep for children under 5 years of age. Retrieved from http://www.who.int/iris/handle/10665/311664

Wu, L., Sun, S., He, Y., \& Jiang, B. (2016). The effect of interventions targeting screen time reduction. Medicine, 95(27), 1-8.

Xu, H., Wen, L. M., Hardy, L. L., \& Rissel, C. (2016). A 5-year longitudinal analysis of modifiable predictors for outdoor play and screen-time of 2- to 5-year-olds. International Journal of Behavioral Nutrition and Physical Activity, 13, 96.

Xu, H., Wen, L. M., \& Rissel, C. (2015). Associations of parental influences with physical activity and screen time among young children: a systematic review. Journal of Obesity, 2015, Article ID 546925. doi:10.1155/2015/546925

Yee, A. Z. H., Lwin, M. O., \& Ho, S. S. (2017). The influence of parental practices on child promotive and preventive food consumption behaviors: a systematic review and meta-analysis. International Journal of Behavioral Nutrition and Physical Activity, 14(1), 47. doi:doi:10.1186/s12966-017-0501-3

Zhao, J., Zhang, Y., Jiang, F., Ip, P., Ka Wing Ho, F., Zhang, Y., \& Huang, H. (2018). Excessive screen time and psychosocial wellbeing: the mediating role of body mass index, sleep duration, and parent-child interaction. The Journal of Pediatrics, 202, 157-162. 
Table 1

Demographic Characteristics of Participants $(N=106)$

\begin{tabular}{|c|c|c|}
\hline \multicolumn{3}{|l|}{ Variables } \\
\hline \multicolumn{2}{|l|}{ Parent's age (years) } & $33.76(5.35)$ \\
\hline \multicolumn{2}{|l|}{ Child's age (years) } & $2.63(1.27)$ \\
\hline & & $\%$ \\
\hline \multirow[t]{2}{*}{ Child's sex } & Male & 46.2 \\
\hline & Female & 53.8 \\
\hline \multirow[t]{3}{*}{ Relationship to child } & Mother & 95.3 \\
\hline & Father & 2.8 \\
\hline & Other & 1.8 \\
\hline \multirow[t]{2}{*}{ Relationship status } & Married/de facto & 95.3 \\
\hline & Separated/divorced/single & 4.7 \\
\hline \multirow[t]{2}{*}{ Household } & Original family & 92.5 \\
\hline & Sole parent/stepfamily/other & 7.5 \\
\hline \multirow[t]{2}{*}{ Number of households ${ }^{a}$} & 1 & 91.8 \\
\hline & 2 or more & 8.2 \\
\hline \multirow[t]{3}{*}{ Number of siblings ${ }^{b}$} & 0 & 41.9 \\
\hline & 1 & 42.9 \\
\hline & $\geq 2$ & 13.4 \\
\hline \multirow[t]{2}{*}{ Parent country of birth ${ }^{c}$} & Australia & 78.4 \\
\hline & Other & 21.6 \\
\hline \multirow[t]{4}{*}{ Parent highest level of education } & High school or less & 19.8 \\
\hline & Trade/college & 13.2 \\
\hline & University degree & 29.2 \\
\hline & Postgraduate degree & 37.7 \\
\hline \multirow[t]{3}{*}{ Parent employment } & Full-time & 20.8 \\
\hline & Part-time/casual & 48.1 \\
\hline & Not working/job seeking & 31.1 \\
\hline \multirow[t]{2}{*}{ Able to meet essential expenses ${ }^{d}$} & Yes & 84.9 \\
\hline & No & 15.1 \\
\hline \multirow[t]{3}{*}{ After expenses can afford } & Not much & 10.4 \\
\hline & Some things & 42.5 \\
\hline & Most things & 47.2 \\
\hline \multirow[t]{2}{*}{ Child of Aboriginal or Torres Strait Islander origin } & Yes & 5.7 \\
\hline & No & 94.3 \\
\hline \multirow[t]{2}{*}{ Professional assistance sought ${ }^{\mathrm{e}}$} & Yes & 9.4 \\
\hline & No & 90.6 \\
\hline
\end{tabular}

Note. Figures are mean (SD) unless stated otherwise.

${ }^{\text {a }}$ Number of households the child lives across, $n=98$ ( 8 missing) 


$$
\begin{aligned}
& { }^{\mathrm{b}} n=105 \text { (1 missing) } \\
& { }^{\mathrm{c}} n=97 \text { (9 missing) }
\end{aligned}
$$

${ }^{\mathrm{d}}$ During the past 12 months; for bivariate analyses this was labelled Financial difficulties

${ }^{\mathrm{e}}$ For the child, for social/emotional/behavioural problems in the past 12 months 
Table 2

Descriptive Statistics for Child Variables $(N=106)$

\begin{tabular}{|c|c|c|c|c|}
\hline Variable & Categories & $\%(n)$ & Mean $(S D)$ & $\begin{array}{c}\text { Median } \\
\text { (min-max) }\end{array}$ \\
\hline \multicolumn{5}{|c|}{ Children's screen time limits (parent reported) } \\
\hline \multirow[t]{5}{*}{ Week day (hours) } & $<1$ hour & $49.3(36)$ & & \\
\hline & 1 hour & $27.4(20)$ & & \\
\hline & 2 hours & $21.9(16)$ & & \\
\hline & 3 hours & $1.4(1)$ & & \\
\hline & 4 hours & - & & \\
\hline \multirow[t]{5}{*}{ Weekend day (hours) } & $<1$ hour & $35.6(26)$ & & \\
\hline & 1 hour & $15.1(11)$ & & \\
\hline & 2 hours & $27.4(20)$ & & \\
\hline & 3 hours & $16.4(12)$ & & \\
\hline & 4 hours & $5.5(4)$ & & \\
\hline \multicolumn{5}{|c|}{ Children's actual screen time (parent-reported) } \\
\hline \multirow[t]{5}{*}{ Week day (hours) } & $<1$ hour & $45.3(48)$ & $1.07(1.17)$ & $1(0-4)$ \\
\hline & 1 hour & $18.9(20)$ & & \\
\hline & 2 hours & $23.6(25)$ & & \\
\hline & 3 hours & $8.5(9)$ & & \\
\hline & 4 hours & $3.8(4)$ & & \\
\hline \multirow[t]{6}{*}{ Weekend day (hours) } & $<1$ hour & $26.4(28)$ & $1.92(2.23)$ & $2(0-19)$ \\
\hline & 1 hour & $20.8(22)$ & & \\
\hline & 2 hours & $19.8(21)$ & & \\
\hline & 3 hours & $19.8(21)$ & & \\
\hline & 4 hours & $8.5(9)$ & & \\
\hline & $\geq 5$ hours & $4.6(5)$ & & \\
\hline Daily average (hours) ${ }^{\mathrm{a}}$ & & & $1.31(1.29)$ & $1(0-7.57)$ \\
\hline \multicolumn{5}{|l|}{ Child behaviour difficulties } \\
\hline STBC Intensity & & & $36.45(18.09)$ & $31.5(18-108)$ \\
\hline CAPES Behaviour & & & $28.41(6.35)$ & $28.66(0-49)$ \\
\hline \multicolumn{5}{|l|}{ Child emotional difficulties } \\
\hline CAPES Emotional Maladjustment & & & $0.69(1.14)$ & $0(0-6)$ \\
\hline
\end{tabular}

Note. STBC: Screen Time Behaviour Checklist (Intensity range 18 - 126); CAPES: Child Adjustment and Parent Efficacy Scale (Behaviour range 0 - 72, Emotional Maladjustment range 0 - 9).

${ }^{a}$ Daily average calculated by (Weekday*5 + Weekend day*2)/7 
Table 3

Descriptive Statistics for Parent Variables $(N=106)$

\begin{tabular}{|c|c|c|c|c|}
\hline Variable & Categories & $\%(n)$ & Mean $(S D)$ & $\begin{array}{l}\text { Median } \\
\text { (min-max) }\end{array}$ \\
\hline \multicolumn{5}{|l|}{ Parenting } \\
\hline \multirow[t]{2}{*}{ PS Laxness } & Normal & $78.3(83)$ & $2.56(0.84)$ & $2.55(1-4.55)$ \\
\hline & $\operatorname{High}^{\text {a }}$ & $21.7(23)$ & & \\
\hline \multirow[t]{2}{*}{ PS Overreactivity } & Normal & $79.2(84)$ & $2.39(0.76)$ & $2.4(1-4.9)$ \\
\hline & High $^{a}$ & $20.8(22)$ & & \\
\hline \multirow[t]{2}{*}{ PS Total } & Normal & $73.6(78)$ & $2.78(0.63)$ & $2.85(1.2-4.37)$ \\
\hline & High $^{a}$ & $26.4(28)$ & & \\
\hline \multicolumn{5}{|l|}{ Parent self-efficacy } \\
\hline STBC Confidence & & & $156.61(27.31)$ & $163(19-180)$ \\
\hline STSES & & & $92.47(26.78)$ & $91.5(25.38-140)$ \\
\hline CAPES Self-Efficacy & & & $160.52(32.97)$ & $168.32(20-190)$ \\
\hline \multicolumn{5}{|c|}{ Parent emotional difficulties } \\
\hline \multirow[t]{5}{*}{ DASS Depression } & Normal & $89.6(95)$ & $3.96(4.93)$ & $2(0-26)$ \\
\hline & Mild & $4.7(5)$ & & \\
\hline & Moderate & $3.8(4)$ & & \\
\hline & Severe & $1.9(2)$ & & \\
\hline & Very Severe & $0(0)$ & & \\
\hline \multirow[t]{5}{*}{ DASS Anxiety } & Normal & $80.2(85)$ & $4.22(4.91)$ & $2.60(0-22)$ \\
\hline & Mild & $6.6(7)$ & & \\
\hline & Moderate & $8.5(9)$ & & \\
\hline & Severe & $2.8(3)$ & & \\
\hline & Very Severe & $1.9(2)$ & & \\
\hline \multirow[t]{5}{*}{ DASS Stress } & Normal & $76.4(81)$ & $10.37(7.36)$ & $9.99(0-34)$ \\
\hline & Mild & $12.3(13)$ & & \\
\hline & Moderate & $6.6(7)$ & & \\
\hline & Severe & $1.9(2)$ & & \\
\hline & Very Severe & $0.9(1)$ & & \\
\hline DASS Distress Total & & & $18.55(14.32)$ & $16(0-70)$ \\
\hline \multicolumn{5}{|c|}{ Parent beliefs about screen time } \\
\hline ECSTS & & & $5.62(1.06)$ & $5.43(3.13-9.61)$ \\
\hline
\end{tabular}

Note. PS: Parenting Scale (subscales and total range $1-7$ ); STBC: Screen Time Behaviour Checklist (Confidence range 18 - 180); STSES: Screen Time Self-Efficacy Scale (range 14 - 140); CAPES: Child Adjustment and Parent Efficacy Scale (Self-Efficacy range 19 - 190); DASS: Depression Anxiety and Stress Scale (subscales range 0 - 42, total range 0 - 126); ECSTS: Effects of Child Screen Time Scale (range $0-10)$. ${ }^{a}$ Elevated range $=\geq 1 S D$ above mean scores for non-clinic population 
Table 4

Correlations Between Child and Parent Variables

\begin{tabular}{|c|c|c|c|c|c|c|c|c|c|c|c|c|c|c|}
\hline & 1 & 2 & 3 & 4 & 5 & 6 & 7 & 8 & 9 & 10 & 11 & 12 & 13 & 14 \\
\hline 1. Child's average screen time ${ }^{\dagger}$ & 1.00 & & & & & & & & & & & & & \\
\hline 2. STBC Intensity ${ }^{\dagger}$ & $.55^{* *}$ & 1.00 & & & & & & & & & & & & \\
\hline 3. CAPES Behaviour ${ }^{\dagger}$ & $.44 * *$ & $.65 * *$ & 1.00 & & & & & & & & & & & \\
\hline 4. CAPES Emotional Maladjustment ${ }^{\dagger}$ & $.22 *$ & 0.14 & $.27 * *$ & 1.00 & & & & & & & & & & \\
\hline 5. PS Laxness & $.32 * *$ & $.42 * *$ & $.25^{*}$ & .14 & 1.00 & & & & & & & & & \\
\hline 6. PS Overreactivity & $.25 * *$ & $.30 * *$ & .18 & -.04 & $.56^{* *}$ & 1.00 & & & & & & & & \\
\hline 7. PS Total & $.35^{* *}$ & $.48^{* *}$ & $.32 * *$ & .10 & $.90 * *$ & $.79 * *$ & 1.00 & & & & & & & \\
\hline 8. STBC Confidence ${ }^{\dagger}$ & $-.28 * *$ & $-.34 * *$ & -.17 & -.05 & $-.44 * *$ & $-.34 * *$ & $-.48 * *$ & 1.00 & & & & & & \\
\hline 9. STSES & $-.50 * *$ & $-.51 * *$ & $-.30 * *$ & -.16 & $-.49 * *$ & $-.43 * *$ & $-.45 * *$ & $.34 * *$ & 1.00 & & & & & \\
\hline 10. CAPES Self-Efficacy ${ }^{\dagger}$ & $-.29 * *$ & $-.43 * *$ & $-.31 * *$ & -.17 & $-.46 * *$ & $-.32 * *$ & $-.48 * *$ & $.74 * *$ & $.43 * *$ & 1.00 & & & & \\
\hline 11. Parent Distress (DASS Total) ${ }^{\dagger}$ & .10 & .07 & -.05 & .11 & $.30 * *$ & $.28 * *$ & $.30 * *$ & -.06 & -.18 & -.02 & 1.00 & & & \\
\hline 12. $\mathrm{ECST}^{\dagger}$ & .08 & -.19 & -.15 & -.01 & -.03 & -.08 & -.04 & .13 & .01 & $.29 * *$ & .00 & 1.00 & & \\
\hline 13. Child age & $.44 * *$ & $.56^{* *}$ & $.64 * *$ & $.31 * *$ & .17 & .09 & $.21^{*}$ & -.17 & -.17 & $-.31 * *$ & -.05 & -.12 & 1.00 & \\
\hline 14. Financial difficulties ${ }^{\dagger}$ & $.23^{*}$ & $.20 *$ & $.22 *$ & -.13 & .17 & .11 & .18 & $-.36^{* *}$ & -.17 & -.09 & .14 & .12 & .11 & 1.00 \\
\hline
\end{tabular}

Note. Pearson's correlations, two-tailed (unless otherwise specified). STBC: Screen Time Behaviour Checklist; CAPES: Child Adjustment and Parent Efficacy Scale; PS: Parenting Scale; STSES: Screen Time Self-Efficacy Scale; DASS: Depression Anxiety and Stress Scale; ECSTS: Effects of Child Screen Time Scale. †Spearman's rank correlation, two-tailed $* p<.05 . * * p<.01$. 
Table 5

Summary of Hierarchical Regression Analysis for Variables Predicting Self-Efficacy for Managing Screen Time

\begin{tabular}{|c|c|c|c|c|c|c|c|c|c|c|c|c|}
\hline \multirow[b]{2}{*}{ Variable } & \multicolumn{3}{|c|}{ Model 1} & \multicolumn{3}{|c|}{ Model 2} & \multicolumn{3}{|c|}{ Model 3} & \multicolumn{3}{|c|}{ Model 4} \\
\hline & $\beta$ & $95 \% \mathrm{CI}$ & $s r^{2}$ & $\beta$ & $95 \% \mathrm{CI}$ & $s r^{2}$ & $\beta$ & $95 \% \mathrm{CI}$ & $s r^{2}$ & $\beta$ & $95 \% \mathrm{CI}$ & $s r^{2}$ \\
\hline \multicolumn{13}{|l|}{ Step 1: Demographic variables } \\
\hline Child age & -.20 & {$[-.42, .01]$} & .041 & -.13 & {$[-.32, .06]$} & .016 & -.06 & {$[-.26, .13]$} & .003 & .01 & {$[-.19, .21]$} & .000 \\
\hline Financial difficulties & -.14 & {$[-.33, .06]$} & .018 & -.06 & {$[-.23, .11]$} & .003 & -.07 & {$[-.24, .11]$} & .004 & -.07 & {$[-.25, .10]$} & .003 \\
\hline Parent education & -.14 & {$[-.34, .06]$} & .019 & -.05 & {$[-.21, .11]$} & .003 & -.04 & {$[-.21, .12]$} & .002 & -.04 & {$[-.20, .13]$} & .001 \\
\hline \multicolumn{13}{|l|}{ Step 2: Parenting variables } \\
\hline Laxness (PS) & & & & $-.29 * *$ & {$[-.51,-.08]$} & .049 & $-.26^{*}$ & {$[-.48,-.03]$} & .034 & -.20 & {$[-.45, .04]$} & .021 \\
\hline Overreactivity (PS) & & & & -.23 & {$[-.49, .03]$} & .036 & -.25 & {$[-.46,-.04]$} & .038 & -.24 & {$[-.51, .02]$} & .037 \\
\hline Self-efficacy (CAPES) & & & & .06 & {$[-.25, .37]$} & .003 & .05 & {$[-.26, .36]$} & .002 & .11 & {$[-.26, .47]$} & .004 \\
\hline \multicolumn{13}{|l|}{ Step 3: Child variables } \\
\hline Emotion problems (CAPES) & & & & & & & -.09 & {$[-26, .09]$} & .006 & -.14 & {$[-.29, .01]$} & .014 \\
\hline Behaviour problems (CAPES) & & & & & & & -.09 & {$[-.29, .11]$} & .005 & .07 & {$[-.21, .36]$} & .002 \\
\hline \multicolumn{13}{|l|}{ Step 4: Screen time variables } \\
\hline Behaviour problems (STBC) & & & & & & & & & & $-.35^{*}$ & {$[-.63,-.07]$} & .058 \\
\hline Self-efficacy (STBC) & & & & & & & & & & -.16 & {$[-.57, .25]$} & .008 \\
\hline Adjusted $R^{2}$ & .055 & & & .263 & & & .262 & & & .318 & & \\
\hline$\Delta F$ & $3.02 *$ & & & $10.62 * * *$ & & & 0.92 & & & $4.99 * *$ & & \\
\hline
\end{tabular}

Note. CI = Confidence interval; PS: Parenting Scale; STBC: Screen Time Behaviour Checklist; CAPES: Child Adjustment and Parent Efficacy Scale. All confidence intervals are calculated with robust standard errors using the HC3 method.

$* p<.05 . * * p<.01 . * * * p<.001$. 
Table 6

Summary of Hierarchical Regression Analysis for Variables Predicting Average Daily Screen Time

\begin{tabular}{|c|c|c|c|c|c|c|c|c|c|c|c|c|c|c|c|}
\hline \multirow[b]{2}{*}{ Variable } & \multicolumn{3}{|c|}{ Model 1} & \multicolumn{3}{|c|}{ Model 2} & \multicolumn{3}{|c|}{ Model 3} & \multicolumn{3}{|c|}{ Model 4} & \multicolumn{3}{|c|}{ Model 5} \\
\hline & $\beta$ & $95 \% \mathrm{CI}$ & $s r^{2}$ & $\beta$ & $95 \% \mathrm{CI}$ & $s r^{2}$ & $\beta$ & $95 \% \mathrm{CI}$ & $s r^{2}$ & $\beta$ & $95 \% \mathrm{CI}$ & $s r^{2}$ & $\beta$ & $95 \% \mathrm{CI}$ & $s r^{2}$ \\
\hline \multicolumn{16}{|l|}{ Step 1: Demographic variables } \\
\hline Child age & $.39 * * *$ & {$[.19, .59]$} & .150 & $.34 * * *$ & {$[.17, .50]$} & .106 & .15 & {$[-.05, .35]$} & .015 & .10 & {$[-.12, .32]$} & .006 & .10 & {$[-.11, .31]$} & .007 \\
\hline Financial difficulties & .16 & {$[-.06, .38]$} & .025 & .10 & {$[-.12, .33]$} & .010 & .11 & {$[-.10, .33]$} & .011 & .03 & {$[-.26, .32]$} & .001 & .02 & {$[-.27, .30]$} & .000 \\
\hline Parent education & -.05 & {$[-.23, .13]$} & .003 & -.12 & {$[-.32, .08]$} & .013 & -.15 & {$[-.36, .06]$} & .020 & -.16 & {$[-.37, .05]$} & .022 & -.17 & {$[-.37, .04]$} & .025 \\
\hline \multicolumn{16}{|l|}{ Step 2: Parenting variables } \\
\hline Laxness (PS) & & & & $.25^{*}$ & {$[.02, .49]$} & .037 & .16 & {$[-.06, .38]$} & .014 & .11 & {$[-.12, .34]$} & .006 & .06 & {$[-.16, .28]$} & .002 \\
\hline Overreactivity (PS) & & & & .08 & {$[-.11, .27]$} & .005 & .11 & {$[-.07, .29]$} & .008 & .12 & {$[-.05, .29]$} & .009 & .06 & {$[-.12, .24]$} & .002 \\
\hline Self-efficacy (CAPES) & & & & -.06 & {$[-.36, .24]$} & .002 & -.03 & {$[-.29, .23]$} & .001 & .11 & {$[-.17, .39]$} & .004 & .14 & {$[-.12, .39]$} & .006 \\
\hline \multicolumn{16}{|l|}{ Step 3: Child variables } \\
\hline Emotion problems (CAPES) & & & & & & & .21 & {$[-.02, .43]$} & .033 & .23 & {$[-.01, .46]$} & .039 & .19 & {$[-.06, .44]$} & .027 \\
\hline Behaviour problems (CAPES) & & & & & & & .26 & {$[-.01, .53]$} & .041 & .15 & {$[-.11, .42]$} & .011 & .17 & {$[-.10, .44]$} & .014 \\
\hline \multicolumn{16}{|l|}{ Step 4: Screen time variables } \\
\hline Behaviour problems (STBC) & & & & & & & & & & .28 & {$[-.01, .56]$} & .036 & .19 & {$[-.07, .45]$} & .016 \\
\hline Self-efficacy (STBC) & & & & & & & & & & -.12 & {$[-.66, .42]$} & .004 & -.16 & {$[-.64, .32]$} & .008 \\
\hline \multicolumn{16}{|l|}{ Step 5: Self-efficacy } \\
\hline Self-efficacy (STSES) & & & & & & & & & & & & & $-.24 *$ & {$[-.47,-.01]$} & .036 \\
\hline Adjusted $R^{2}$ & .172 & & & .256 & & & .336 & & & .368 & & & .401 & & \\
\hline$\Delta F$ & $8.28 * * *$ & & & $4.84 * *$ & & & $6.92 * *$ & & & $3.46^{*}$ & & & $3.36^{*}$ & & \\
\hline
\end{tabular}

Note. CI = Confidence interval; PS: Parenting Scale; STBC: Screen Time Behaviour Checklist; CAPES: Child Adjustment and Parent Efficacy Scale; STSES: Screen Time Self-Efficacy Scale. All confidence intervals are calculated with robust standard errors using the HC3 method.

${ }^{*} p<.05 .{ }^{* *} p<.01 . * * * p<.001$ 